\title{
El contacto lingüístico. ¿Enfermedad de las lenguas?
}

\section{Lingüistic contact. A language illness?}

\author{
María Antonieta Flores Ramos (México) \\ ninasgerais@hotmail.com \\ Universidad Intercultural de Chiapas
}

\section{Resumen \\ El presente artículo destaca los errores idiomáticos que se producen tanto en el habla del español de los Altos de Chiapas como en la escritura de estudiantes de la región. El estudio atribuye al contacto lingüístico, al dialecto castellano regional y al aprendizaje informal del español, el desconocimiento del español estándar por parte de los estudiantes. Finalmente, destaca las consecuencias del empleo del español no estándar en la escritura con algunos ejemplos concretos.}

Palabras clave: contacto lingüístico, español estándar y no estándar, dialecto, escritura.

\begin{abstract}
The following article remarks on the idiomatic errors produced in the Spanish variant of Altos de Chiapas as well as in the written expression of the students of the region. This study attributes the lack of knowledge of standard Spanish to the lingüistic contact, the regional Castilian dialect and informal learning of Spanish. Finally, The article highlights the consequences of non- standard Spanish usage in writing with some concrete examples.
\end{abstract}

Keywords: Lingüistic contact, standard and non-.standard Spanish, dialect, writing

\section{FECHA DE RECEPCIÓN: 12 de septiembre de 2012 FECHA DE REVIIIÓN: APROBACIÓN:}

Para citar este artículo / to cite this article Flores Ramos, M. El contacto lingüístico. ¿̇Enfermedad de las lenguas?, Poliantea, 8(15), 173-198. 
- El contacto lingǘstico - María Antonieta Flores Ramos 


\title{
El contacto lingüístico. ¿Enfermedad de las lenguas?
}

\author{
María Antonieta Flores Ramos (Colombia) \\ Universidad Intercultural de Chiapas. Maestra en Lingǘrstica Aplicada \\ de la Universidad Federal de Minas Gerais.
}

\section{Introducción}

Distintos estudios sobre el estado de Chiapas señalan un común denominador: la década de los setenta como un periodo detonador de grandes cambios socioculturales en este estado. Uno de los fenómenos que ha dado lugar a estos cambios, se debe a los sorprendentes e impredecibles desplazamientos poblacionales de las últimas décadas. Este hecho, nada novedoso en la historia de México, ha llamado la atención de los medios masivos de comunicación y, en la agenda de muchos centros de investigación, se ha constituido como uno de los temas más abordados. La prensa ha llamado la atención en torno a la migración, sobre todo, al considerar que el monto de las remesas enviadas por los inmigrantes conforma un ingreso importante - sino el único- de muchas familias mexicanas.

En Chiapas, dichos desplazamientos poblacionales tuvieron lugar abiertamente luego de que el régimen colonial alteró la distribución de la población maya, debido a la política colonial de reordenamiento espacial de los pueblos indígenas. No obstante, en las últimas décadas, estos desplazamientos han sido ocasionados por causas tan diversas como la colonización desorganizada de la tierra, las expulsiones religiosas, los levantamientos militares internos y externos (desplazamientos de indígenas guatemaltecos ocasionados por la guerra civil), la falta de fuentes de trabajo e inclusive desplazamientos debidos a siniestros, como la explosión del volcán Chichonal (1982) o las inundaciones ocasionadas por el huracán Stan (2005). 
Si las migraciones internas han existido siempre, lo que, en todo caso, ha cambiado son los tipos de flujos migratorios indígenas del campo a la ciudad, es decir, a zonas periféricas de ciudades, convencionalmente, denominadas ladinas como lo es la ciudad de San Cristóbal de Las Casas. El asentamiento de amplios sectores indígenas en las últimas décadas ya no es debido al trabajo temporal de los indígenas en esta ciudad o al anhelo de integrarse a la "sociedad nacional". Motivos diversos han ocasionado el desplazamiento de indígenas a San Cristóbal de Las Casas: el más conocido, las expulsiones religiosas de evangelistas, debidas (por lo menos en lo discursivo) al cambio de creencias religiosas (en el caso de Chamula, por ejemplo). De los años setenta a la actualidad, lo que comenzó por la construcción de la colonia Nueva Esperanza creció notoriamente conforme el flujo de expulsados aumentaba; de ello da cuenta Robledo Hernández, al hablarnos de la creación de nuevas colonias en los alrededores de San Cristóbal:

En un inicio estas colonias comenzaron tímidamente como trazos de unas cuantas cuadras. [...] pero a medida que los inmigrantes fueron llegando, aparecieron nuevas colonias hacia el noroeste de la ciudad: San Antonio de Los Montes, La Hormiga, Getsemaní, Diego de Mazariegos y, en otros puntos, La Quinta, Santa Cruz Cascajal y, más tarde, Paraíso, Nueva Palestina, Nueva Tlaxcala, Morelos, Benito Juárez, La Selva, Artículo 115 y el Ex-Carmen (Robledo, 2007, p. 111).

El arribo a San Cristóbal de Las Casas de cientos de personas procedentes de comunidades indígenas, por lo tanto, no se debió más a una decisión individual o a la provisión de mano de obra temporal, sino que, a partir de los años setenta, su establecimiento fue permanente e intensivo, lo que generó grandes cambios en el estilo de vida y la organización sociocultural:

Con la llegada de los expulsados, por primera vez se asentaron en San Cristóbal miles de indígenas que no habían escogido dejar sus pueblos, que guardaban la esperanza de retornar a ellos y que no se habían planteado la posibilidad de abandonar su lengua y su identidad local. Con la ayuda de las iglesias protestantes, recrearon en la periferia de San Cristóbal y en algunas localidades de Teopisca unas comunidades indígenas de un nuevo tipo, más abiertas, menos jerárquicas, más participativas que veían con normalidad la diversidad religiosa y cuyo sostén económico ya no era más el trabajo de la tierra, sino la albañilería, la artesanía, el 
comercio, los transportes y los servicios (Viqueira, 2002, p. 359).

Al establecer una tipología de las migraciones internas de los indios de Chiapas, Cruz Burguete nos habla de los desplazados por motivos de guerra, refiriéndose a las familias que no se aliaron al levantamiento zapatista del 94 y, consecuentemente, se desplazaron a otros lugares, de modo que,

[...] las ciudades que más resintieron la llegada de estos desplazamientos [fueron] Comitán, Las Margaritas, San Cristóbal, Ocosingo y Palenque [las cuales] vieron aumentar hasta el doble su población urbana en tan sólo cuatro años después de la sublevación indígena” (2007, p. 67).

Como resultado de dichos cambios poblacionales, Cruz Burguete (2006, p. 36) destaca el desempleo, el bajo ingreso salarial, una fuerte oleada de migrantes chiapanecos a la Unión Americana, la escasez de opciones de trabajo en el campo, la masificación educativa y la ruptura de la unidad familiar y comunitaria. A este respecto, su conclusión más importante es que "la comunidad indígena de hoy, ya no corresponde a las formas de organización cerrada implantadas durante el período colonial (Cruz Burguete, 2006, p. 50).
Dichos desplazamientos poblacionales han captado nuestra atención por los nuevos cambios identitarios que generaron, por la masificación educativa y porque se relacionan con el contacto sociocultural de grupos étnicos, pero esta vez, de una forma, aparentemente, más abierta, heterogénea, intensiva y duradera. Los asentamientos de grupos indígenas migrantes se han dado, como en muchas otras ciudades latinoamericanas, en los antes, considerados, alrededores de la ciudad. Este fenómeno sociocultural ha dado lugar, asimismo, a la interrelación de dos sistemas lingüísticos que se influyen, mutuamente.

Mucho se ha hablado de la manera en que las lenguas mayas han sido influidas por la lengua de Estado y del constante embate de esta por desprestigiarlas y restituirlas de su, cada vez más, reducido espacio. No obstante, la manera en que, en sentido inverso, el castellano de Los Altos de Chiapas ha sido influido por las lenguas mayas, con las que cotidianamente convive, es un asunto poco atendido por los investigadores de esta región.

La transferencia de rasgos atribuibles a las lenguas amerindias ha sido, con todo, ampliamente documentada 
por estudios, como los de Palacios (1997), quien analiza la variante del español en zonas de influencia guaranítica. $\mathrm{Al}$ analizar algunos morfemas verbales que han sido transferidos del guaraní al español coloquial de Asunción, la autora destaca que "el español paraguayo ha integrado en su estructura gramatical numerosos morfemas verbales guaraníes cuya función consiste en matizar la actitud del hablante, del mensaje o de la realidad que los rodea" (1997, p. 6).

En México, encontramos también estudios respecto de los efectos recíprocos del contacto de lenguas, como los de Juan Antonio Flores (1995), quien expone algunos resultados relacionados con el bilingüismo náhuatl-español, tomando en cuenta distintos niveles de análisis lingüístico. Asimismo, en el español yucateco, hay estudios sobre la influencia del sustrato maya, como los de Rosa Leme (1995), quien, al abordar el ordenamiento de las palabras y la prosodia oracional, concluye que "algunas tendencias naturales de la lengua española [...] pueden verse reforzadas en contacto con la lengua maya" (1995, p. 424).

La tesis de que algunas características propias del español pueden ser reforzadas por influencia de las lenguas con las cuales tiene contacto es una de las que más cobran sentido a la luz de un examen de los trabajos escritos por los estudiantes bilingües (español-lengua amerindia) y monolingües (español) de esta región. Siete años de experiencia laboral, en la revisión de los trabajos escritos de estos estudiantes, me indican que los errores de redacción exceden la hipótesis del aprendizaje deficiente de una segunda lengua (en lo sucesivo L2), pues, estas incorrecciones idiomáticas son igualmente visibles en el español escrito de estudiantes monolingües y en el habla corriente de las personas de esta región. Lo anterior no es un fenómeno aislado y único, sino que, como lo señala Palacios (1997), es propio del dialecto español de regiones con contacto lingüístico histórico; más aún, la autora considera que estos cambios se deben a los efectos recíprocos entre el español y alguna lengua amerindia, más que a un mal aprendizaje:

No cabe duda de que las variedades de español habladas por bilingües en áreas de contacto histórico muestran variaciones lingüísticas significativas que inciden en la fonética o en la morfosintaxis, como hemos visto. Sin embargo, estos cambios pueden registrarse 
igualmente en hablantes monolingües de español en esas áreas, por lo que el argumento del bilingüismo como causa directa de un "mal aprendizaje" del español no deja de ser una falacia (1997, p. 11).

En lo sucesivo, el objetivo de este estudio será identificar algunas de las características más recurrentes de estas redacciones que pueden atribuirse, o bien, ser reforzadas por la influencia del sustrato maya y que comienzan a caracterizar la variedad dialectal del español alteño1. No obstante, antes de pasar al análisis y ejemplificación de dichas características, aclararemos algunos conceptos como el de interferencia y contacto lingüístico que más que fenómenos separados son fenómenos codependientes. Posteriormente, presentaremos algunos ejemplos de dialectos del español influidos, de algún modo, por una lengua amerindia, extraídos principalmente de Lastra (2003), Leme (1995) y Flores (1995). Asimismo, expondremos uno de los estudios más conocidos sobre el español de

1 Este nombre, "español alteño", me lo sugirió el doctor Giles Polian Marcus en una asesoría acerca del proyecto de investigación, el 22 de noviembre de 2011 en el Centro de Investigaciones y Estudios Superiores en Antropología Social (Ciesas) Sureste.
San Cristóbal (Francis, 1960) del cual presentaremos algunos ejemplos todavía vigentes en el español alteño. Finalmente, contrastaremos los ejemplos presentados con las incorrecciones idiomáticas más comunes en la redacción de los estudiantes universitarios; pero, además, contraponiéndolos con enunciados en lenguas mayas, de los cuales se destacarán algunas características morfosintácticas. Los ejemplos se enfocarán, en principio, a analizar el empleo de los posesivos (y dobles posesivos), el uso irregular del género y de los pronombres átonos, en el entendido de que este tema requiere un estudio más extenso y a diferentes niveles. Cabe destacar que, en este estudio, el término interferencia se entiende como la transferencia inconsciente al habla de algún rasgo de una lengua donadora a una receptora adoptada sea por bilingües (español-lengua amerindia), o bien por monolingües que la han heredado de su entorno, pues como ya se mencionó, en zonas de contacto lingüístico histórico, las características del dialecto español están ampliamente extendidas entre ambos grupos. Por su parte, las interferencias lingüísticas heredadas o generadas por la influencia del entorno son 
visibles especialmente en el habla, pero su presencia es también evidente en la escritura, dado que, entre los estudiantes, no hay una clara diferenciación entre el código hablado y el escrito.

\section{El contacto lingiǘstico}

El término interferencia es un vocablo procedente de la física que se ha trasladado a otras ramas de la ciencia que ha adquirido ciudadanía propia, sin dejar, por ello, de ser un término difuso. En física, el vocablo designa "cualquier proceso que altera, modifica o destruye una onda durante su trayecto en el medio en que se propaga" (Domínguez, 2001, p. 1). También se entiende como "el encuentro de dos movimientos ondulatorios cuyo contacto da lugar a un reforzamiento o a una anulación" (Domínguez, 2001, p. 1). El vocablo se ha empleado en muchas disciplinas y, en el campo de la lingüística, se entiende por interferencia, en sentido muy general, el traslape de dos lenguas en el que una lengua (donadora o L1) traspasa algunas de sus características a otra lengua (receptora o L2). La interferencia lingüística generalmente se asocia al campo léxico, pero los elementos trasladados pueden ser de orden fonológico, morfológico y sintáctico, pues, no solo se prestan las palabras, sino que, cuando surge la mezcla exacta de condiciones sociales y lingüísticas, "todos los aspectos de la estructura lingüística son susceptibles de transferirse de una lengua a otra" (Thomason, 2001, p. 11). Así, la transferencia puede generarse en todas las áreas de la estructura lingüística, como en la fonología (sistema de sonidos), en la estructura de las palabras (morfología) o en la estructura de la oración (sintaxis).

Este fenómeno también se asocia al contacto que un hablante tiene con dos sistemas lingüísticos diferentes, es decir, con el bilingüismo. Los rasgos de la lengua sustrato pueden trasladarse, asimismo, a una tercera lengua; por lo cual, la interferencia lingüística es característica de un multilingüismo donde las lenguas se influyen mutuamente. La interferencia lexical, entendida sea como préstamo, calco o neologismo, llega, con el uso, a naturalizarse entre los hablantes y pasa, de ser un rasgo momentáneo e individual, a una adopción permanente, cobijada por una comunidad lingüística a través de un dialecto.

La interferencia lingüística suele ser negativamente valorada. Su 
empleo es considerado como una desviación de la norma, incompatible con la lengua estándar y motivada por la incapacidad del hablante en el dominio de dos sistemas lingüísticos diferentes. La interferencia lingüística, sin embargo, hace parte de un fenómeno mucho más amplio denominado contacto lingüístico, el cual, a pesar de su cotidianeidad y permanencia, genera controversia. Como destaca Winford (2003, p. 1), la mezcla entre lenguas:

[...] ha suscitado siempre reacciones emocionales fuertes como la ridiculización, la condena apasionada o el rechazo absoluto. Los puristas la han censurado por considerarla una aberración de la "lengua correcta" y esta actitud se refleja en la percepción popular de la mezcla de lenguas como desviadas de la norma, corruptas e inclusive sin el estatus de una verdadera lengua.

Ciertamente, desde los albores de la humanidad, los seres humanos hablaron más de una lengua. Por lo cual, como destaca Thomason (2001, p. 6), estas se han mantenido en contacto desde hace miles de años. El contacto lingüístico, aunque aparentemente fácil de definir, debe contener ciertas constantes, pues, no solo se trata de una interacción comunicativa temporal entre individuos donde hay involucrado más de un código lingüístico. En este caso, cabría incluir el lenguaje de señales de los sordomudos. Se trata de una interacción social prolongada entre miembros de diferentes comunidades lingüísticas que, en general, mantienen cercanía. De lo contrario, como lo señala Winford (2003, p. 3), podría considerarse una situación de contacto lingüístico, un encuentro esporádico entre turistas de comunidades lingüísticas distintas. En muchos casos, la interacción social prolongada entre miembros de diferentes comunidades lingüísticas, "puede resultar en distintos tipos de mezclas [e inclusive] en el cambio estructural de alguna de las lenguas" (Winford, 2003, p. 3).

Como lo han destacado distintos estudios, el contacto lingüístico puede tener una amplia variedad de resultados; comenzando, en algunas situaciones, con el préstamo exiguo de vocabulario, "mientras que otras situaciones de contacto pueden conducir a la creación de lenguas enteramente nuevas" (Winford, 2003, p. 2). Thomason (2001, p. 10) concluye que el contacto lingüístico es la norma, y lo verdaderamente excepcional sería encontrar una lengua cuyos hablantes evitaran el contacto 
con hablantes de otras lenguas por cuando menos dos siglos. El asunto, sin embargo, provoca calurosos debates, especialmente entre los llamados puristas. Ajenos a la cotidianeidad, permanencia e importancia del papel que la mezcla de lenguas desempeña en el desarrollo las lenguas humanas, "incluidas aquellas consideradas modelo de corrección y pureza" (p. 10), algunos puristas han considerado los resultados del contacto lingüístico como procesos anómalos que las desvirtúan, alejándolas, por ello, de la norma. En realidad, la mezcla de lenguas "es un proceso creativo gobernado por ciertas normas, que afecta, en grados diferentes, a todas las lenguas" (Thomason, 2001, p. 11). Por eso, para Thomason (2001, p. 11), estas lenguas, más que el testimonio de un desvío o error, son el testimonio de la creatividad humana ante la necesidad de romper las barreras lingüísticas para crear un medio común de comunicación.

En un estudio de Poplack y Sankoff (citado por Lastra, 2003, p. 193) acerca de las alternancias entre francés e inglés en hablantes canadienses, los investigadores advierten que las interferencias se dan porque, a veces, hay una palabra (le mot just) o enunciado (an equal opportunity employer) considerado más expresivos en una lengua que en otra. Es decir, hay posturas que consideran el "error" como algo positivo en la medida en que es un recurso creativo para manifestar afectividad o mayor expresividad y que, por lo tanto, presupone la evolución natural de una lengua, cuyos resultados llegan a los hablantes a través de una herencia de la cual no siempre están conscientes.

Aunque la influencia de una lengua sustrato sobre una receptora, en un ambiente donde predomina el bilingüismo, no únicamente se relaciona con los préstamos léxicos, la mayoría de los estudios se han centrado en las interferencias léxicas, es decir, en los préstamos que el castellano, por poner un caso, adquiere del náhuatl o, viceversa, en los préstamos que el aimara emplea del español. En resumen, los estudios se concentran en la interferencia lexical mutua que hay entre el español y las lenguas amerindias. Sin embargo, entre más prolongado sea el contacto lingüístico entre estas lenguas, mayor influencia recíproca habrá en todos los niveles lingüísticos.

Muestra de la influencia gramatical de una lengua amerindia sobre el castellano la encontramos en 
Lozano (citado por Lastra, 2003, p. 211), quien estudia el sustrato quechua sobre el español no estándar de Perú, o bien, en los estudios de Quant e Irigoyen (citado por Lastra, 2003, p. 215) sobre el denominado guaraní de resistencia hablado en el nordeste de Argentina. Estos autores agregan que en el español no estándar, hablado por monolingües, descendientes de guaranís cuya castellanización se impuso como una exigencia sociopolítica, se manifiesta la influencia de una lengua sustrato. Estos monolingües, pertenecientes a clases populares y habitantes de suburbios urbanos afirma- "aprendieron un castellano sin modelos académicos" (citado por Lastra, 2003, p. 215). Estudios de este tipo son importantes porque, en la actualidad, los cambios lingüísticos van en constante aumento, $y$ esto tiene repercusiones en una de las tareas de la educación formal, es decir, en la adquisición del código escrito. Paradójicamente, la influencia de una lengua sustrato sobre el español no estándar no ha sido estudiada a fondo más en el léxico, o bien, ha sido señalada como el sello folclorista de una variante dialectal que hunde sus raíces en el español arcaico.
En todo caso, las interferencias de distintos niveles debidas, entre otras cosas, a la influencia de la lengua sustrato han sido estigmatizadas o señaladas como una enfermedad de las lenguas que tiene sus orígenes casi exclusivamente en el español arcaico. A este respecto, cabe destacar los comentarios de Nardi respecto de la indiferencia que ha ocasionado el papel del sustrato indígena en la formación del español americano.

Los filólogos y lingüistas romanistas han mostrado, en general, una tendencia a minimizar el papel del sustrato indígena en la formación del español americano porque estudian el español culto de las grandes ciudades. Además, se ha hablado del "español americano" como si fuera uno solo. Se califica de mala traducción la influencia de las lenguas indígenas en el español y se apela a ella solo luego de agotar todas las posibilidades de explicación mediante las "tendencias" del español. Cuando mucho, se acepta que la lengua indígena haya desempeñado el papel de catalizador de algún proceso de origen hispánico (Nardi, citado por Lastra, 1992, p. 212).

Uno de los estudios más conocidos sobre el español de San Cristóbal es el de Susana Francis (1960), 
denominado Habla y literatura popular en la antigua capital chiapaneca. Tal vez porque la mezcla de condiciones sociales y lingüísticas no se había dado en la época, la autora no atribuye a las lenguas mayas de la región una influencia categórica sobre el español de San Cristóbal. Más bien, según se constata en el capítulo "Formación de los barrios", lo considera heredero del español colonial. A este respecto afirma:

Cuxtitali es el barrio de habla más típica, tanto por su acento, como por sus giros de lenguaje que evocan, de manera notable, el español del siglo XVII (Francis, 1960, p. 34). Ahora, recordemos el origen de los colonizadores españoles que forman el elemento más importante en la constitución del habla local (Francis, 1960, p. 35).

Aunque muy tímidamente la autora afirma que, "a pesar de la influencia opuesta, también los pueblos indígenas han ejercido su influencia en la formación del habla que nos ocupa" (p. 45), es decir, en el habla del español de San Cristóbal. No obstante, el libro carece de ejemplos que ilustren esta afirmación y, más bien, nos presenta un contexto sociolingüístico muy distinto al de la segunda década del siglo XXI, pues, afirma que casi todas las transacciones comerciales se llevaban a cabo en una lengua indígena dado que muy pocos indígenas hablaban español:

Poquísimos de ellos hablan "castilla" y los que lo hacen tienen un acento extraño, porque es idioma que aprendieron tardíamente. [...] Como a los coletos les es muy necesario comunicarse con ellos, casi todos hablan "lengua", principalmente los comerciantes, aun los pocos de origen extranjero que radican allá, por lo que casi todas las transacciones se llevan a cabo en tal idioma (Francis, 1960, p. 44).

Con todo, el estudio incluye muchos ejemplos que tienen plena vigencia relacionados con las características que nos corresponde analizar. Este, consta de un apartado donde, a partir de ejemplos del discurso hablado, la autora analiza los procesos fonológicos del habla popular, el voseo y las características morfológicas y sintácticas del español alteño de los años cincuenta. Al hablar de los posesivos, la autora manifiesta que "estos se prodigan innecesariamente" (p. 93) en frases como "Ponételo tu vestido". Del mismo modo, añade que San Cristóbal es una región loísta, pues, - respecto del empleo de pronombres acusativos y dativos- el lo se emplea en 
lugar de le y la y, "además se usa prolijamente en casos que no requieren el auxilio de pronombres" (p. 90), como en "Lo limpié la mesa".

Dado que el lenguaje hablado y escrito son códigos estrechamente vinculados en el imaginario del estudiante, es oportuno analizar la redundancia de posesivos y dobles posesivos en los textos escritos revisados. Como Francis lo menciona, muchas veces la repetición del posesivo es superflua, pues, cuando, este está implícito, es innecesario resaltar la pertenencia (Grijelmo, 2006, p. 136). Por eso, este autor considera el pleonasmo como "una supuración, un grano que rebosa materia viscosa por acumulación de grasa, algo feo". De tal modo, señala como una incorrección escribir "El jugador se lesionó su tobillo izquierdo", pues, caemos en un pleonasmo o redundancia de significado puesto, que solo puede lesionarse su tobillo, no el de otra persona. Por lo tanto, lo correcto sería, "El jugador se lesionó el tobillo izquierdo".

El doble posesivo, no obstante, a veces se emplea para evitar la anfibología o ambigüedad de significados, producidos, principalmente, por el posesivo su. Por eso, dice Gili y Gaya:
[...] para remediar la vaguedad que resulta de este pronombre posesivo, el idioma se vale del recurso de añadir a su el nombre del poseedor, o el pronombre que le representa, acompañado de la preposición $d e$, siempre que pueda haber duda: Su casa de Luis (mejor:"La casa de Luis"); su casa de ellos, su casa de usted (Vivaldi, 2000, p. 93).

Más adelante Vivaldi (2000, p. 93) afirma que esta tendencia de la época clásica (refiriéndose al empleo del doble posesivo) "se mantiene en el habla moderna, pero con visible tendencia a limitarla a su de usted y su de ustedes". Sin embargo, Vivaldi (2000, p. 93) atribuye las posibles anfibologías del $s u$ a la pobreza del idioma, pues, en idiomas como el francés y el alemán, la terminología pronominal es más completa e, inclusive, en el caso del segundo, el posesivo empleado depende del número de poseedores $\mathrm{y}$, del género y número de estos:

En realidad, en lo que se refiere al $s u$, la culpa de las ambigüedades resultantes hay que achacárselas a la pobreza del idioma. Los franceses tienen "son", "sa", "leur", "leurs". En nuestro idioma todo se reduce a su y sus. Para evitar confusiones, pues, conviene, según los especialistas del lenguaje $1^{\circ}[\ldots]$ colocar el $s u$ de tal suerte que se refiera al nombre anterior más cercano [y] $2^{\circ}$ hacer 
construcciones indirectas pronominales. Así en vez de "Se le llenaron sus ojos de lágrimas", conviene escribir: "Se le llenaron los ojos de lágrimas” (2000, p. 93).

La posesión, por su parte, es un fenómeno gramatical que casi nunca se relaciona con la apropiación real de algo o de alguien, sino solo con la apropiación psicológica. Cecilio Tuyuc (2001, p. 110) analiza esta categoría gramatical en las lenguas mayas, en su Gramática descriptiva jacalteca. Al hablarnos de los sustantivos siempre poseídos, afirma que "su característica principal es que siempre son poseídos y se refieren a partes muy ligadas a la naturaleza de una persona, animal o cosa [como en] mi pie, tu lengua, su hoja". Por su parte, Nora England (1996, p. 82), al referirse al posesivo, afirma que "las palabras que pertenecen a esta clase, generalmente nombran a partes del cuerpo humano, a parientes $y$, a veces, a ropa y comida”. En el caso del jacalteco, dice Tuyuc (2011), la omisión del posesivo en este tipo de sustantivos provoca que la palabra tenga un significado totalmente diferente, pues en lugar de decir mi pie, tu lengua, su hoja diremos coyote, bejuco y sarro, respectivamente. De tal modo, es difícil pensar que la redundancia del posesivo no se deba a la influencia de las lenguas indígenas, especialmente, al abordar trabajos sobre la posesión inalienable o bien análisis, como los de Lozano (citado por Lastra, 2003, p. 210), quien estudia la forma en que el quechua influye al español, comparando oraciones del español no estándar de Ayacucho con el limeño estándar. Entre los ejemplos correlacionados con el español de Los Altos de Chiapas, encontramos el uso del doble posesivo, como en la oración siguiente:

\begin{tabular}{|c|c|c|}
\hline $\begin{array}{c}\text { Español no estándar de } \\
\text { Ayacucho }\end{array}$ & $\begin{array}{c}\text { Español estándar } \\
\text { limeño }\end{array}$ & $\begin{array}{c}\text { Doble } \\
\text { posesivo }\end{array}$ \\
\hline $\begin{array}{c}\text { 1. Era su amiga de } \\
\text { Juan. }\end{array}$ & Era la amiga de Juan & \\
\hline
\end{tabular}

Lozano (2003) afirma, respecto de este ejemplo, que en "en quechua el posesivo se puede expresar efectivamente de manera doble". De modo que, la traducción literal de una oración, como "ñuqapa wasiy", sería "De yo mi casa" con lo cual, "es lógico que un hablante de quechua diga "Su amiga de Juan" en vez de "La amiga de Juan" (citado por Lastra, 2003, p. 212). Los hispanistas, agrega el autor, dirán que "en zonas fuera de la influencia del quechua también se encuentra esta 
construcción. Pero no cabe duda de que el quechua por lo menos la refuerza" (p. 212). La misma observación sería aplicable respecto de la influencia de las lenguas mayas en el español de San Cristóbal: si estas no influyen directamente en su estructura gramatical, por lo menos refuerzan algunas de sus características. Con todo, la redundancia de posesivos no deja de verse como una supuración o una mácula que, aunque inadvertida para quien escribe, resulta demasiado recargada para el que lee. El ejemplo siguiente, extraído del trabajo de uno de los estudiantes, amén de demostrar un abuso del posesivo $m i$, refleja un empleo inadecuado del pronombre átono $l o$, pues, en ocasiones, este no corresponde al género y número del objeto directo al que sustituye. Independientemente de que el texto hace patentes errores de otra índole, nuestro propósito es señalar, en negritas, el empleo exagerado del posesivo, así como la falta de concordancia de género, pues, de esta característica hablaremos posteriormente.

Mi metodología de la investigación son los pasos que lo llevaré a cabo para realizar mi proyecto de investigación es decir primero haré un inventario o descripción detallados de las acciones que yo lo voy a ejecutar con los tiempos y los recursos a mi alcance, siendo que con esa información lo voy a formular mi cronograma de actividades porque es muy necesario para realizar mi proyecto de investigación para mi tesis2.

El ejemplo anterior nos recuerda la afirmación de Francis (1960) respecto de que San Cristóbal es una zona loísta. En efecto, el loísmo, según el Diccionario panhispánico de dudas (2005), es el uso impropio del pronombre átono $l o(s)$ "en función del complemento directo masculino (de persona o de cosa) o neutro (cuando el antecedente es un pronombre neutro o toda una oración), en lugar de $l e(s)$ que es a la forma a la que corresponde ejercer esta función". La misma fuente agrega que este uso impropio de los pronombres átonos de tercera persona surge cuando no queda claro para el hablante si el complemento verbal es directo o indirecto.

Sin embargo, los errores en el empleo del pronombre átono lo en el español de Los Altos no se relacionan,

2 Extraído de una redacción de Francisco Zepeda Hernández con su previa autorización. 
exclusivamente, con el desconocimiento del tipo de complemento (directo o indirecto), sino con la falta de concordancia de género y número en relación con el complemento directo. Por lo tanto, encontramos una simplificación pronominal, pues, en situaciones donde normalmente el pronombre átono debería ser femenino (cuando el complemento directo es un sustantivo femenino), o bien masculino (cuando el complemento directo es un sustantivo masculino) se emplea, de manera indistinta y cada vez más generalizada, el pronombre átono lo. Lo anterior, como podemos observarlo en el ejemplo, sin considerar la falta de concordancia de número (singular o plural), es decir, si el complemento al que sustituye el pronombre es un sustantivo singular o plural. Esta característica, cada vez más corriente en el español de San Cristóbal, se hace extensiva al dativo o complemento indirecto; esto es, el pronombre átono lo sustituye tanto a le como a su respectivas forma plural les.

La utilización correcta del $l o$, en el español alteño, es más bien fortuita, y la diferencia con los complementos, a los cuales sustituye, es que el empleo de unos está más estigmatizado que el de otros. Dicha simplificación pronominal está cerca de ser naturalizada en el español alteño tanto entre los castellanohablantes monolingües como entre los bilingües, cuando el complemento directo al cual sustituye el pronombre átono es femenino o masculino. Azucena Palacios (1997), en una observación respecto de esta característica, afirma lo siguiente:

[...] la simplificación del sistema pronominal átono que se da en algunas áreas, peruanas, ecuatorianas, mexicanas o guatemaltecas, esto es, la tendencia a utilizar un único pronombre "lo" para objeto directo sí está estigmatizada y se ha convertido en un marcador sociolingüístico asociado con la variedad de bilingües sin instrucción formal (p. 9).

La falta de concordancia de género podría reforzarse a causa de que en las lenguas mayas no hay género; pero en la redacción también observamos un uso de doble complemento directo (u objeto directo), como en "los pasos que lo llevaré a cabo". Es interesante señalar que estas características se encuentran también entre el español de Sudamérica y se les atribuye a la influencia de las lenguas amerindias de esa región. Por ejemplo, Gutiérrez Marrone (citado por Lastra, 2003, p. 210) estudia 
la influencia del quechua y el aimara en el español de Bolivia. Respecto de la falta de concordancia de género y delo uso redundante de objetos directos, el autor citado comenta:

[...] en el español popular de la zona [refiriéndose a La Paz y Cochabamba] es frecuente el uso de $l o$ redundante junto al objeto directo expreso y sin concordancia de género y número [lo cual] se podría atribuir a la influencia del quechua o el aimara.

El autor ejemplifica estos usos con oraciones comunes en el español de monolingües de distintos grados escolares, como en "Dámelo la pelota" (con falta de concordancia de género) o como en "La gente joven quiere dominarlo a sus padres" (con falta de concordancia de número). Estos ejemplos que demuestran el uso redundante de objeto directo y la falta de concordancia de género (y número) son curiosos, porque parecerían extraídos del español de monolingües de Los Altos de Chiapas. En una radiodifusora de San Cristóbal de Las Casas3, a propósito de tratarse de un programa emitido el Día de las Madres en México

3 XEW noticiero de las dos de la tarde, 10 de mayo de 2009.
(10 de mayo), uno de los locutores le preguntó al otro si había felicitado a su madre, de esta manera: " $i Y a$ lo felicitaste a tu mamá?" Aquí hay un lo redundante porque, si dentro del discurso ya se habló de un tema o antecedente (la madre), es innecesario introducir el lo. Además, de ser introducido, como se trata de un objeto directo femenino (la madre, tendría que emplearse el pronombre femenino la con lo cual, de acuerdo con el español estándar, la pregunta sería “¿Ya la felicitaste?”, o bien “¿ya felicitaste a tu mamá?". Esta falta de concordancia de género podría deberse a la influencia de las lenguas originarias de la región, pues, tal como sucede con el aimara y el quechua, en las lenguas mayas no existe el género.

Lozano (citado por Lastra, 2003, p. 210), al analizar la forma en que el quechua influye al español peruano, compara oraciones del español no estándar de Ayacucho con el limeño estándar. En las oraciones siguientes, advertimos el uso del doble objeto directo (o complemento directo) y la falta de concordancia de género entre este (el objeto directo) y el pronombre átono que lo sustituye: 


\begin{tabular}{|c|l|l|}
\hline $\begin{array}{c}\text { Español no estándar de } \\
\text { Ayacucho }\end{array}$ & \multicolumn{1}{|c|}{$\begin{array}{c}\text { Español estándar } \\
\text { limeño }\end{array}$} & \\
\hline $\begin{array}{l}\text { 2. Él es el médico que la } \\
\text { curó a mamá }\end{array}$ & $\begin{array}{l}\text { Él es el médico que } \\
\text { curó a mamá }\end{array}$ & $\begin{array}{l}\text { Doble } \\
\text { objeto } \\
\text { directo }\end{array}$ \\
\hline $\begin{array}{l}\text { 3. A María nosotros lo } \\
\text { adoramos. }\end{array}$ & $\begin{array}{l}\text { A María nosotros la } \\
\text { adoramos. }\end{array}$ & Género \\
\hline
\end{tabular}

Flores (1995) considera la repetición del complemento directo como una réplica o interferencia morfosintáctica "que no hace más que recordarnos la obligatoriedad morfológica que el Nahuátl tiene por marcar la transitividad" (p. 500). Es decir, el náhuatl, a diferencia del español, "requiere indicar morfológicamente en el verbo la naturaleza transitiva del sintagma verbal mientras que en español la misma función se marca por medios sintácticos" (p. 500). Para ilustrar esta característica, ofrece dos ejemplos donde el objeto directo se replica; primero, mediante el pronombre átono, antecediendo al verbo $y$, posteriormente, de forma expresa, posponiéndolo -al verbo-. Cabe destacar que, en el segundo ejemplo, el pronombre átono lo sustituye a un complemento indirecto o dativo; lo cual representa un uso cada vez más extendido en el español alteño que tiende a reproducirse en la escritura:
12. ¿Lo quieres café? (En vez de “quieres café?”.)

13. Lo fue decir L. (En vez de "Le fue a decir a L”.) (Flores, 1995, p. 5001).

Los resultados alcanzados hasta ahora nos remiten a otra de las conclusiones de Rosa Leme respecto de la influencia del maya en el español yucateco, es decir, que "al lado de los importantes cruces fonéticos y léxicos entre el maya y el español, el entrecruzamiento sintáctico es también notorio, intenso y sistemático" (1995, p .424). Valdría la pena entonces llevar a cabo un estudio más amplio sobre la posible influencia del orden de los afijos que indican transitividad en las lenguas mayas de Los Altos de Chiapas, pues, en tsotsil4 hay una serie de marcas morfológicas o bien un juego de afijos pronominales que se aglutinan al verbo transitivo, con el fin de indicar la relación agentepaciente (B'aa'yil, citado por Vázquez, 2012). Un estudio de este tipo ha sido realizado por María Elena Sánchez Arroba quien, en su artículo "Ergatividad en la familia lingüística maya”, analiza la influencia

4 El tsotsil junto al tseltal son las dos lenguas mayas habladas en la región Altos de Chiapas. 
de la sintaxis del maya yucateco en el español de Yucatán (2008, p. 541). Estas evidencias nos remiten, nuevamente, a otra de las conclusiones de Rosa Leme (1995), quien supone que "el reforzamiento en lo tocante a orden y aspecto ocurra también en las demás variantes del español que viven en contacto con la lengua maya" (p. 155). Dicha interferencia, en el orden sintáctico, la advertimos en un estudio sobre gramática donde Fernández, Martínez y Moreira, (2000, p. 5) destacan el orden básico de los constituyentes en el tsotsil de Zinacantan colocando como ejemplos una cláusula intransitiva (verbo-sujeto) y una clausula transitiva (verbo-paciente-agente).

Chamem xa li jtot e.

Cham- -em xa li j- tot-e morir EST. ADV. ART. $1^{\text {a }}$ POS. padre ENCL.

"Mi padre ya ha muerto" 'Oy sna li jtot e.

'Oys- -na li j--tote

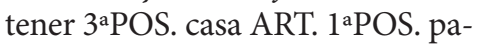
dre ENCL.

"Mi padre tiene una casa"

En la traducción palabra por palabra, advertimos el orden, la función y el significado de cada constituyente. Convencionalmente, estas autoras traducen los respectivos enunciados siguiendo el orden básico de los constituyentes en español, es decir, sujeto-verbo-objeto; no obstante, en el habla cotidiana informal del español san cristobalense, es factible escuchar expresiones, como "Murió ya mi papá" o bien "Tiene su casa mi papá", sin que por ello sea un habla estigmatizada en este contexto. Cabría aclarar, entre otros factores, las características de las personas que introducen en el habla el rema antes que el tema para determinar si se trata, efectivamente, de una interferencia sintáctica del tsotsil o si, como señala Susana Francis (1960), son "arcaísmos derivados de las viejas formas del español" (p. 22), o bien una mezcla de ambos todavía no explorada.

Por último, analizaremos una categoría inexistente en las lenguas mayas de Los Altos de Chiapas, es decir, el género. En lo respectivo al género, Grijelmo (2006) nos dice que se trata de un fenómeno exclusivamente gramatical (p. 102), el cual no siempre coincide con el sexo y, más bien, funciona al margen de esa condición biológica (p. 103). En buena medida, añade Grijelmo, el género femenino coincide con el sexo femenino $y$, el género masculino, suele designar a seres del sexo masculino, pero "es posible decir la ballena aunque se 
trate de una ballena macho, o la ardilla, o la jirafa. [...]. Lo mismo podemos decir el ratón, el moscón o el topo, aunque estemos refiriéndonos a una hembra" (p. 105).

También encontramos sustantivos epicenos que no varían su forma para el masculino o el femenino, como en una cría, una serpiente, un cuervo (2006, p. 105). Por eso, Flores (1995) afirma que, debido a la arbitrariedad en la asignación de los valores masculino y femenino, y a la correlación del género con la categoría semántica de sexo, en ocasiones, los hablantes bilingües de español-náhuatl "buscan marcas fónicas o 'culturales' para adjudicar el género" (1995, p. 500). De tal modo, a la palabra collar o carnaval se les adjudica el género femenino "por la terminación [ar] de collar y [al] de carnaval", como en la collar rosa, o la carnaval, o bien, por considerar que tocar el violín es un oficio exclusivamente masculino, se dice el violinisto (p. 501).

\section{Consecuencias en la escritura}

Al igual que en los ejemplos expuestos, en el español de Los Altos de Chiapas, los estudiantes se guían por las marcas fónicas, por lo cual a veces escriben enunciados. como "la mapa" en vez de "el mapa". No obstante, los errores en la asignación del género son más prolíficos en el empleo del pronombre átono. Este uso irregular del género gramatical, del posesivo $-\mathrm{y}$ doble posesivo-, además del empleo del doble complemento directo atribuible o no a la influencia de las lenguas mayas de la región, cuando se aplica a los textos escritos crea una ambigüedad difícil de dilucidar si no se conoce el contexto de los estudiantes. Asimismo, en el lenguaje escrito, la redundancia es innecesaria, pues, escribir no significa transcribir la propia oralidad, lo cual, como observa Ferreiro (1995, p. 110), "contribuye a desprestigiar las variantes dialectales orales que más se alejan de la norma ortográfica".

En la escritura, por lo tanto, "no hay pasaje directo de lo oral a lo escrito, sino mediado por una reconstrucción de lo oral" (Ferreiro, 1995, p. 110). Si bien el estándar se caracteriza por su flexibilidad y se refiere a la forma de lengua considerada, tácitamente, como la más adecuada en contextos formales de uso (Bernárdez, 1999, pp. 33-59), dicho "consenso social" suele ser más conservador cuando se presenta de manera escrita y cuando es probatorio 
de la adquisición de un conocimiento mediante un trabajo "formal". En tales casos, debemos reconocer la conveniencia de que haya un español en el que nos entendamos por escrito todos los usuarios de la lengua. Por lo tanto, este debe atenerse, en la medida de lo posible, a la norma estándar, y evitar la interferencia de registros y de rasgos propios de la variante dialectal del entorno; pues, aunque lo anterior sea efectivo en el español hablado, origina ambigüedad en la escritura.

La ambigüedad generada por el desconocimiento de la lengua estándar y por la inexperiencia para expresarse en el código escrito no es un problema exclusivo del español escrito en Los Altos de Chiapas. $\mathrm{Si}$ analizamos la literatura sobre el tema, advertiremos que se trata de un problema no solo de la denominada educación intercultural, sino de la educación en su conjunto, encontrado no únicamente en México sino también en otras latitudes, como España y Brasil. Basta abordar las primeras páginas del libro de Cassany Enseñar lengua para constatarlo:

El aumento del analfabetismo funcional, es decir, la ineptitud que presentan alumnos escolarizados normalmente para resolver cuestiones elementales relacionadas con la lengua escrita, la estrecha relación entre dificultades del lenguaje y fracaso escolar, y la observación directa de jóvenes y adolescentes incapaces de salir airosos de situaciones cotidianas que implican una cierta elaboración intelectual, tiene que obligarnos a pensar que hay algo en la escuela que no funciona como debería hacerlo (1998, p. 11).

En todo caso, dice Cassany, se trata del aprendizaje de una lengua -lengua 1 o 2 - en una situación a menudo desfavorable, donde "la variedad dialectal [de la zona] presenta una distancia importante con respecto a la variedad como estándar" (1998, p. 11). Tal es el caso del español alteño, el cual, a juzgar por la revisión continua de los trabajos escritos, es una variante que tiende a alejarse cada vez más del español estándar de México. El desconocimiento del denominado estándar genera incorrecciones idiomáticas en la escritura, y estos conflictos con la lengua no competen, únicamente, a los estudiantes bilingües, pues, en la práctica, usualmente es imposible distinguir si nos hallamos ante un texto escrito por un estudiante monolingüe o bilingüe. Si a esto le agregamos la falta de contacto con la cultura escrita, sea por cuestiones culturales o sea por falta 
de familiaridad con la lectura, el resultado redunda en la ambigüedad e imprecisión de los textos, ya que, como señalamos anteriormente, es indispensable conocer el contexto personal de los estudiantes para poder entender su redacción.

\section{A guisa de conclusión}

En San Cristóbal de Las Casas comienza a consolidarse, o bien un español local, un español alteño común a todos los hablantes, sean castellanohablantes monolingües $o$ bilingües (hablantes del español y alguna/s lengua/s maya/s). El habla local de esta región hace parte de la diversidad y de la vitalidad de las lenguas. Además de dar cuenta de la creatividad de los hablantes, nos permite analizar los cambios de una lengua en un momento dado del tiempo o, por lo menos, en dos periodos importantes: los años cincuenta, según lo destaca Susana Francis en su obra, y la segunda década de este siglo. No obstante, vale destacar que el español de San Cristóbal es un dialecto estigmatizado, especialmente cuando se transfiere al código escrito como si la escritura fuera simplemente una transcripción del habla.

La mezcla social y lingüística exacta está dada para que los cambios lingüísticos se produzcan o, por lo menos, para que ciertas características del español local se refuercen debido al contacto de este con las lenguas mayas de la región. El contacto entre castellanohablantes y hablantes de lenguas mayas, en la actualidad, no es temporal, sino intensivo y duradero, pues, estos no se comunican exclusivamente en una especie de pidgin para efectuar transacciones comerciales, sino que los mayahablantes residentes en San Cristóbal son casi en su totalidad bilingües y mantienen relaciones de trabajo permanentes con los castellanohablantes, no solo como proveedores de mano de obra temporal, sino como prestadores de servicios permanentes. Debido a las migraciones internas, intensificadas por lo menos desde los años setenta, residen en ciertas colonias de esta ciudad, y la proveen de servicios como la albañilería, la artesanía y el servicio doméstico, entre otros. Su presencia, por ello, no es solo temporal $y$, consecuentemente, el contacto entre los dos sistemas lingüísticos es permanente. A ello nos referimos al afirmar que la mezcla exacta de condiciones sociales y lingüísticas está dada para que se produzcan cambios lingüísticos más notorios. 
Estas interrelaciones sociales donde el individuo convive cotidiana y prolongadamente con más de un código lingüístico producen interferencias lingüísticas, comunes a las situaciones de contacto lingüístico. Consecuentemente, como lo destaca Francis (1960), el español hablado en San Cristóbal se caracteriza, o bien por prodigarse innecesariamente en el empleo de posesivos, o bien por ser una región loísta. Lo cierto es que estas dos características se han visto reforzadas por el contacto con las lenguas mayas de la región. Influencias atribuibles a las lenguas indoamericanas están ampliamente documentadas en el español yucateco, pero, asimismo, ya en el español guaraní, ya en el español peruano y boliviano. Todos los ejemplos citados aquí se correlacionan con el español alteño hablado en San Cristóbal de Las Casas, además de relacionarse con el mismo tipo de desviaciones en relación con la lengua estándar. Si bien el término lengua estándar suele ser flexible y la noción de lo que es adecuado pertenece a la pragmática más que a la morfosintaxis o a la semántica, hay una conveniencia de comprendernos en el español escrito, para el que hay una normativa a la cual deben atenerse, especialmente los escribientes (Bernárdez, 1999, p. 39). Lo preocupante es que las características del español alteño hablado se traslapen a la escritura no porque el habla no deba ser creativa, versatil y espontánea, sino porque la escritura representa un código más conservador, cuyo objetivo es garantizar la comunicación entre los usuarios de una lengua y asegurar su permanencia, de una manera relativamente más estable que el habla. Por lo tanto, la escritura debería apegarse, en la medida de lo posible, al español estándar a través de una mediación reflexiva de lo que se va a escribir. Sin embargo, la escritura, en un ambiente donde no "se acostumbra leer", parece ser más bien una transcripción del habla, lo cual la aleja notablemente del español estándar al tiempo que contribuye a la estigmatización del dialecto hablado.

Por lo analizado en el español sudamericano, las interferencias lingüísticas son más manifiestas en los lugares con contacto lingüístico histórico donde la población, mayoritariamente bilingüe, ha sido informalmente castellanizada por imposiciones sociopolíticas. En San Cristóbal, como ya mencionamos, 
esta interacción se ha vuelto permanente y las interferencias no aluden exclusivamente a las interferencias léxicas, pues, resulta insuficiente afirmar que bolo, pox o tsucum provienen de tsotsil, ya que hay interferencias morfológicas y sintácticas que, aunque invisibles para el castellanohablante común, son más penetrantes y permanentes que las anteriores.

Finalmente, estimamos que, para determinar el surgimiento de un español tsotsilizado, la investigación requiere un enfoque sociolingǘstico para definir los factores lingüísticos, sociales y económicos más determinantes de los hablantes. De tal modo, habría que procurar responder a ciertas preguntas, como la manera en que se estructuran socialmente los rasgos mayanizantes, considerando, igualmente, aspectos, tales como la fase etaria, el nivel de escolaridad y sociocultural del hablante. Asimismo, para garantizar que el desconocimiento del español no estándar se debe a la adquisición del español sin modelos académicos, habría que emplear un enfoque sociolingüístico con diferentes variables.

Provisionalmente, estimamos que la diferencia entre una redacción, notablemente alejada del español estándar, y una redacción aceptable se debe al contacto cotidiano con la cultura escrita. Asimismo, estimamos que el desconocimiento del español estándar no se debe, sin más, a un aprendizaje informal del español, sino a un incipiente cambio lingüístico cada vez más generalizado en la región, pues, a menudo, es muy difícil persuadir a un estudiante de lo que la gramática normativa indica cuando en su ambiente sonoro se habla con incorrecciones idiomáticas cada vez más naturalizadas.

\section{Referencias}

Bernárdez, E. (1999). ¿Qué son las lenguas. Madrid: Alianza Editorial. Cassany, D.; Luna, M. y Sanz, G. (1998). Enseñar lengua. Barcelona: Graó.

Cruz Burguete, J. et al. (2007). Las migraciones internas de los pueblos indígenas de Chiapas. México: Ecosur-UNICH.

Real Academia Española (2005). Diccionario panhispánico de dudas [en línea]. Consultado el 14 de junio 2012 en $<\mathrm{http} / /$ :buscon.rae.es/dpd1/>.

Domínguez Vásquez, M. J. (2011). En torno al concepto de interferencia [en línea]. Universidad Santiago de Compostela. Consultado el 1 de 
febrero de 2012 en <www.ucm.es/ info/circulo/no5/dominguez.htm>.

Fernández Gómez, M. A.; Martínez Balladares, B. y Moreira Sendón, M. (2000). El tzotzil de Zinacanteco: resumen gramatical. Vigo: Universidade de Vigo.

Ferreiro, E. (1995). La reconstrucción de lo oral en el proceso de adquisición de la escritura. En Arzápalo Marín, R. y Lastra, Y. (comps.) Vitalidad e influencia de las lenguas indígenas en Latinoamérica (pp. 106-116). México: UNAM-IIA.

Flores, J. A. y Valiñas, L. (1995). Algunos efectos recíprocos del contacto náhuatl-español en el centro de Guerrero. En Arzápalo Marín, R. y Lastra, Y. (comps.) Vitalidad $e$ influencia de las lenguas indígenas en Latinoamérica. México: UNAM-IIA.

Francis, S. (1960). Habla y literatura popular en la antigua capital chiapaneca. México: Instituto Nacional Indigenista (INI).

Grijelmo, A. (2006). Gramática descomplicada. Madrid: Taurus.

Lastra, Y. (2003). Sociolingüistica para hispanoamericanos. Una introducción. México: El Colegio de México.
Leme, R. (1995). Un elemento de influencia del sustrato maya en el español yucateco: el ordenamiento de palabras. En Arzápalo Marín, R. y Lastra, Y. (comps.) Vitalidad e influencia de las lenguas indígenas en Latinoamérica. México: UNAM-IIA. Martín Vivaldi, G. (2000). Curso de redacción. Teoría y práctica de la composición y del estilo. México: Cengage Learning Editores.

England, N. (1996). Introducción a la lingüística de los idiomas mayas. Guatemala: Editorial Cholsamaj.

Palacios Alcaine, A. (1997, 21-25 de octubre). Situación de contacto lingüístico en Hispanoamérica: español y lenguas amerindias. I Simposio Internacional sobre Bilingüismo. Vigo.

Sánchez Arroba, M. E. (2008). Ergatividad en la familia lingüística maya. Memorias del IV Foro Nacional de Estudios en Lenguas. Universidad de Quintana Roo: Fonael.

Thomason, Sarah. G. (2001). Language contact: an introduction. Washington: George Town University Press.

Tuyuc Susuc, C. (2001). Gramática descriptiva jacalteca (popti). 
Guatemala: Academia de Lenguas Viqueira, J. P. (2002.). Encrucijadas Mayas. chiapanecas. México: Tusquets.

Vázquez López, M. R. La ergativi- Winford, D. (2003). An introducdad en lengua tsotsil. México: Cela- tion to contact linguistics. Reino li [en línea]. Consultado el 20 junio Unido: Blackwell Publishing. de 2012 en <www.celali.gob.mx/ergatividad-tsotsil.htm $>$. 